\title{
Users' Abilities and Performance in Dictionary Look Up ${ }^{1}$
}

\section{Zoe Gavriilidou}

Democritus University of Thrace

zgabriil@helit.duth.gr

\section{Abstract}

The purpose of the present study was to focus on dictionary users' abilities and performance during receptive dictionary use. Forty eight students of the Democritus University of Thrace were given a worksheet containing fifteen phrases, all including a polysemous word typed in bold characters, and the Dictionary of Standard Greek of Manolis Triandafyllidis. The subjects were told to look up the bold words in the dictionary and write down their meaning as well as the exact position of the entry where the specific meaning was found. The results revealed that users located more easily in dictionaries noun and verb meanings than adjective meanings. It was also found that it was difficult for the students to locate the meaning of phraseologies. These findings support the idea of adopting specific training programs for raising dictionary use awareness.

\section{Introduction}

Dictionaries are important reference materials which can be used in various circumstances (e.g during reading comprehension, text production, grammar activities, oral discussions, etc) and which can become, under conditions, a valuable learning aid. However, dictionary consultation is a complex process that requires specific skills and strategies. Recent research has studied not only the strategies required for dictionary consultation (Cowie 1999, Fan 2000, Nesi \& Haill 2002, Wingate 2004) but also the variables which affect strategy use during dictionary searches such as proficiency level, the type of dictionaries, the

1 I would like to thank the anonymous reviewer for his/her comments which improved the initial text.

\section{(cc) BY-NC-ND}


task performed, etc (Wingate 2004, Nesi \& Hua Tan 2011). The present paper focuses on the specific strategies employed during receptive dictionary use.

\section{Literature Review}

Receptive dictionary use, in other words dictionary use mainly while reading a text and secondarily while listening to an oral text appears to be the most popular use of dictionaries (Béjoint 1981, Cowie 1999, Gavriilidou 2002, Scholfield 2002).

According to Scholfield (1999) in receptive situations, an unfamiliar word or phrase is sought in monolingual or bilingual dictionaries, consequently the sole piece of information targeted is meaning.

Receptive dictionary use involves five main steps (Bogaards 1993, Scholfield 1999):

- Identification in the text of an unknown word or phrase

- Decision to use a dictionary in order to resolve that problem and selection of an appropriate dictionary type

- Lemmatization, that is finding the citation form of inflected forms found in the text

- Localization of the correct part of the entry where different meanings of the same wordform are included

- Integration of the found meaning back in the initial text or other task where the problem arose.

However, a number of problems related with each one of the above mentioned steps may arise during dictionary look up. For instance, very often during receptive dictionary use the users fail to identify the unknown words of a text either because these words have a deceptive morphological structure or they are polysemous words whose one meaning is known to the user but not the one in the current context or they are false friends between two languages or parts of phrasal idioms (Laufer 1997). In other cases, in receptive situations users avoid using dictionaries because they consider them too difficult to deal with. Instead, they simply skip the unknown words or ask the teachers for clarifications or in some cases they try to infer word meaning from context (Hosenfeld 1977). And even when they choose to use a dictionary, they often select an inappropriate type of dictionary or they face problems with lemmatization or localization of the appropriate entry or part of the entry. For instance, users select the first definition in a polysemous entry (Nesi \& Haill 2002, Nesi \& Hua Tan 2011) or they tend to select familiar segments from the entry (Müllich 1990 cited in Wingate 2004). These errors in receptive use "result in the learner not finding the information needed though in fact it is there, or the learner may end up with some misunderstandings" (Scholfield 1999: 19). 
In order to resolve these problems during receptive use, the dictionary user has to apply in each step different strategies which will help him/her achieve an effective look up.

\subsection{Strategies for Unknown Word Identification}

Effective readers do not simply classify words into known and unknown; Instead, they bear in mind that some words may look familiar but are in reality false friends, parts of idioms or polysemous words which need to be looked up, otherwise there is a danger of text misunderstandings. Consequently, while processing a text, the reader should first draw a list with the unknown words to be looked up in the dictionary. Once the words are looked up in the dictionary, the reader should return to the text and try a second reading of it by exploiting the information found in dictionary as well the information (s) he considers to be known. If comprehension problems still persist, then (s)he should re-examine the text elements (s)he considers familiar by verifying their meaning in the dictionary.

\subsection{Strategies for Deciding When to Use a Dictionary and What Type of Dictionary}

Recent research (Gu \& Johnson 1996, Nation 2001, Oxford 1990, Schmitt 1997) has shown that dictionary use is an important vocabulary strategy that a) occurs successfully in conjunction with guessing (or inferencing) and note-taking, b) provides information about a specific item, and c) has a positive influence on the learner's acquisition process (Hulstjin 1993, Luppescu \& Day 1993, Knight 1994, Laufer \& Hadar 1997, Laufer \& Hill 2000, Bruton 2007). However, excessive dictionary use may, on the other, hand inhibit users from developing other important strategies such as guessing, or asking for clarifications. Therefore, users should develop strategies for deciding when dictionary use is the optimal choice. Scholfield (1999), for instance, claims that the importance of an item is a reliable criterion if someone is about to choose whether to look up a word or not. More precisely, unknown words in titles or at the beginning of a text, content words frequently used in a text should be candidates for dictionary searches.

As far as the selection of the appropriate dictionary type is concerned, research has mainly focused on the eventual advantages and disadvantages of bilingual vs. monolingual dictionaries. For instance, a lot of researchers consider that bilingual dictionaries can cause errors or problems during text understanding (Ard 1982, Hartmann 1987, Nation 2001, Summers 1995), while others claim that the effectiveness of the bilingual or monolingual dictionaries 
depends on the nature of task to be solved or the level of the learner (Laufer $\&$ Hadar 1997). While bilingual dictionaries are more appropriate for beginners and during translation tasks from mother tongue to the second/ foreign language, monolingual dictionaries are more useful for the advanced level since they provide more detailed information. In any case, users should be aware of the different dictionary types and the specific categories of information found in them through special instruction programs.

\subsection{Lemmatization Strategies}

Users should be able identify morphological indices (stems, prefixes, suffixes, inflectional morphemes) of the unknown word in order to make hypotheses about the look-up form of that word. To do so, they should first have acquired morphological awareness. In case of oral texts, users have to make hypotheses about possible spellings of the unknown words based on their knowledge of writing conventions of their mother tongue or their second/foreign language. Additionally, dictionary users should acquire basic abilities of alphabetical sequencing through teaching and practice, otherwise lemmatization is not possible.

\subsection{Strategies for Appropriate Entry or Subentry Selection and Integration of the Correct Meaning Back in the Initial Text}

Nesi \& Haill (2002) have shown that dictionary users often accept the first definition given for a polysemous word, even when this is not appropriate in the context. This happens because "the first definition is the first users read, so choosing it shortens their dictionary consultation time, and it is also because the first definition usually represents the most familiar meaning, and is thus most likely to confirm any knowledge they already have about the meaning of the word" (Nesi \& Haill 2002: 79). However, skilful users, when they realize, while looking up a word, that the specific word has more than one meaning, they check one by one all the meanings to eliminate the unsuitable one and chose the appropriate one for a given context.

Lexical phrases, idioms and complex words, on the other hand, are also difficult to locate in a dictionary, because it is difficult for a user to decide which headword to look them under. Users should be able to make inferences about the dictionary entries in which to look up such items and shouldn't give up their searches when they cannot find a word in the place they thought it would be. According to Scholfield (1999) dictionary users should be prepared to scan to the end of an entry to find a subentry for compound words or idioms. 


\section{Purpose and Rationale}

The purpose of the present study was to investigate receptive dictionary use and more precisely dictionary user's ability to select the correct meaning of a given word as well as the parameters such as speech part, polysemy, and frozenness which affect users' selection of the appropriate or inappropriate entry.

\section{Method}

\subsection{Participants}

Forty eight first year students of the preschool education department of the Democritus University of Thrace participated in the study. As students were mainly females and shared the same age, the influence of sex and age were not studied in the present paper.

\subsection{Instrumentation and Procedure}

Participants were given a worksheet (see appendix I) containing fifteen phrases, all including a polysemous word typed in bold characters, and the Dictionary of

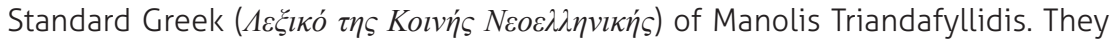
were told to look up the bold words in the dictionary and then select and write down the meaning of the dictionary which corresponded to the meaning of the word in each phrase of the questionnaire. They were also required to note the exact position of the dictionary entry where the specific meaning was found. There was no time restriction for the completion of the task.

The distribution of task items across speech parts is presented in Table 1.

Table 1.

Distribution of items across speech parts

\begin{tabular}{|l|l|}
\hline SPEECH PARTS & N \\
\hline NOUNS & $\mathbf{4}$ \\
\hline VERBS & 7 \\
\hline ADJECTIVES & $\mathbf{4}$ \\
\hline TOTAL & 15 \\
\hline
\end{tabular}

The items included in the task were the following: two different meanings of the

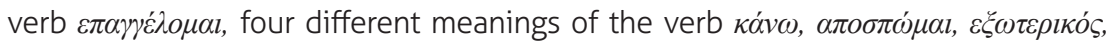

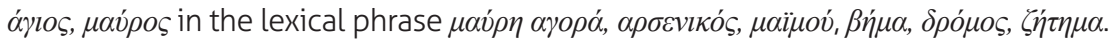




\subsection{Scoring}

Each correct search was accredited one point. Correct searches were considered the ones in which the users noted in the worksheet the correct meaning of the item word as well as the right part of the dictionary entry where that meaning was found. Erroneous searches received zero points. Erroneous answers were the ones in which the user either provided an inappropriate meaning of the entry word or did not locate the target word or meaning in the dictionary.

\subsection{Data Analysis}

Descriptive statistics, such as frequencies, were used to check the percentage of correct or erroneous answers for each item of the experimental task. Comparisons between the correct and erroneous answers for each item were made by using chi-square test. Comparisons of the mean scores between nouns and verbs, nouns and adjectives and verbs and adjectives were made using a paired t-Test with alpha set at .001 .

\section{Results}

Table 2.

Frequency of errors in each item.

\begin{tabular}{|c|c|c|c|c|c|}
\hline ITEMS & CORRECT & WRONG & CORRECT \% & WRONG \% & $x^{2}$ \\
\hline 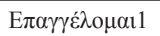 & 47 & 1 & 97.9 & 2.1 & $44.08 *$ \\
\hline Ел $\alpha \gamma \gamma \varepsilon \dot{\lambda} \circ \mu \alpha 12$ & 40 & 8 & 83.3 & 16.7 & $21.33 *$ \\
\hline 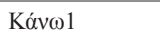 & 30 & 18 & 62.5 & 37.5 & 3.00 \\
\hline 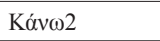 & 39 & 9 & 81.2 & 18.8 & $18.75^{*}$ \\
\hline Kóvஸ3 & 34 & 14 & 70.8 & 29.2 & 8.33 \\
\hline Kóvฒ4 & 46 & 2 & 95.8 & 4.2 & 40.33* \\
\hline А $\pi 0 \sigma \pi \dot{\mu} \mu \alpha$ & 39 & 9 & 81.2 & 18.8 & $18.75 \%$ \\
\hline 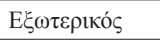 & 17 & 31 & 35.4 & 65.1 & 4.08 \\
\hline A $\gamma 1 \alpha$ & 35 & 13 & 72.9 & 27.1 & 10.08 \\
\hline 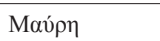 & 2 & 46 & 4.2 & 95.8 & 40.33* \\
\hline Арбвvıкós & 41 & 7 & 85.4 & 14.6 & $24.08 *$ \\
\hline Bí $\mu \alpha$ & 43 & 5 & 89.6 & 10.4 & $30.08 *$ \\
\hline$\Delta \rho \mu_{\mu}{ }^{\prime}$ & 35 & 13 & 72.9 & 27.1 & $10.08 *$ \\
\hline Maïнov́ & 39 & 9 & 81.2 & 18.8 & $18.75^{*}$ \\
\hline 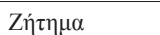 & 41 & 7 & 85.4 & 14.6 & $24.08 *$ \\
\hline
\end{tabular}

$* p<.001$ 
Table 3.

Mean scores for noun, verb and adjective dictionary searches

\begin{tabular}{|l|c|c|}
\hline Part of Speech & Mean & SD \\
\hline Noun searches & .82 & .15 \\
\hline Verb searches & .82 & .19 \\
\hline Adjective searches & .50 & .25 \\
\hline
\end{tabular}

The mean score for noun and verb searches was higher than for adjective searches. The paired t-test analysis showed significant differences between noun and adjective searches ( $t=7.04, p<.001)$ and verb and adjective searches $(t=7.3, p<.001)$. In other words, users located easier noun and verb meanings than adjective meanings.

\section{Discussion}

The purpose of the present study was to investigate receptive dictionary use. Results showed that users looked up effectively 10 out of 15 sample words (66\%). More precisely the successful word searches concerned the task-items

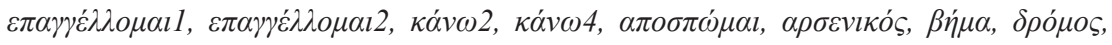
$\zeta \dot{\eta} \tau \eta \mu \alpha, \mu \alpha \ddot{\mu} \mu о v$. All of these words were polysemous but none of them was part of a lexical phrase or idiom. This finding might suggest that users of our sample do not tend to choose the first in the list meaning of a polysemous word. On the contrary they make use of semantic, syntactic or other cues to be guided in the appropriate meaning selection of a polysemous word. Thus, in our study, polysemy did not seem to affect users' abilities in receptive dictionary use. This result is not consistent with previous research (Nesi \& Haill 2002, Neubach \& Cohen 1988) who found that subjects tend to take into consideration only the first meaning in dictionary entries of polysemous words. This difference might be explained however by the fact that the sample of our study consisted of Education Department students who had the opportunity to practice dictionary use during their studies.

No statistical differences were found between the correct and erroneous

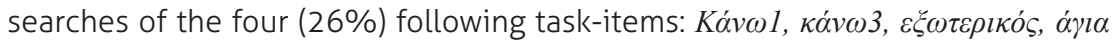
which means that users provided an almost equal number of successful and unsuccessful dictionary consultations for these words. These task-items either present in context a metaphoric meaning $(\alpha \gamma l \alpha)$ or they form lexical phrases

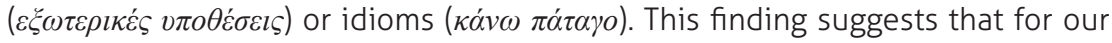
sample the major source of errors in dictionary look-ups were metaphorical meanings, lexical phrases and idioms. This result is consistent with previous 
research carried out by Wingate (2004) who also found that lexical phrases and idioms caused problems in her sample. The difficulty in locating an idiom or lexical phrase, clearly indicates that the participants in that study had poor knowledge or dictionary conventions.

Users failed to locate only one word (6\%), the word $\mu$ av́p $\eta$ as part of the lexical

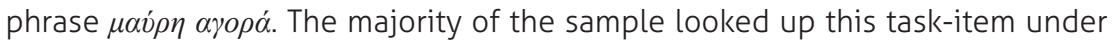

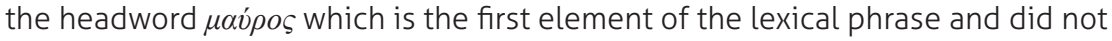
manage to find relevant information. Only two subjects searched also under the second element $\alpha \gamma o \rho \alpha$ which is the semantico-syntactic head of the lexical phrase. Bogaards (1990) found differences between Dutch and French learners in their spontaneous approach to the look up strategies of lexical phrases or multiword compounds. Béjoint (1981) reported that learners of English show a preference for searching under the last content word. In any case, the above mentioned result indicates that the users of our sample gave up when they did not manage to find the phrase under the headword they look it up.

Finally, the results showed that users located easier noun and verb meanings than adjective meanings. This happened probably because three of our four task adjectives had a metaphorical meaning or belonged to lexical phrases.

\section{Conclusions and Further Investigation}

The purpose of the present paper was to study receptive dictionary use. Results showed that users encountered problems mainly during look ups of lexical phrases or metaphorical meanings and revealed that the subjects lack basic strategies for dealing with such problems. This finding lends support to the idea of designing special dictionary training programs which would raise dictionary user's strategy awareness.

The present study focused on receptive dictionary use. However, more research is needed into the strategies required not only for receptive but for productive dictionary use as well. Furthermore, the effect of the part of speech on successful dictionary search has to be further investigated with the help of better proportioned test items. Finally, dictionary strategies of Greek users should be studied with a larger sample including subjects with different professional orientation and educational background. 


\section{References}

Ard, J. 1982. The use of bilingual dictionaries by ESL students while writing. Review of Applied Linguistics 58: 1-27.

Béjoint, H. 1981. The Foreign Student's Use of Monolingual English Dictionaries. Applied Linguistics 2(3): 207-22.

Bogaards, P. 1990. Où cherche-t-on dans le dictionnaire? International Journal of Lexicography 3(2): 79-102.

Bogaards, P. 1993. Models of Dictionary Use. Dutch Contributions to AlLA '93. Amsterdam: Free University: 17-28.

Bruton, A. 2007. Vocabulary learning from dictionary referencing and language feedback in EFL Translational Writing. Language Teaching Research 11: 413-431.

Cowie, B. 1999. English dictionaries for foreign learners. Oxford: Clarendon Press.

Fan, M. 2000. The dictionary look-up behavior of Hong-Kong students: a large scale study. Education Journal 28 (1): 123-138.

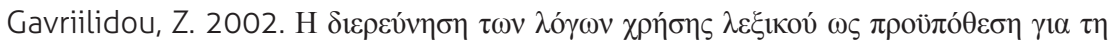

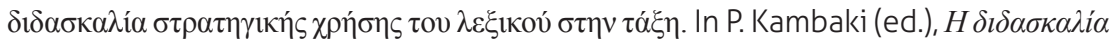

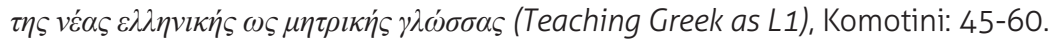

Gu, P.Y. and Johnson, R.K. 1996. Vocabulary learning strategies and language learning outcomes. Language Learning 46: 643-679.

Hartman, R.R.K. 1987. Four perspectives on dictionary use: A critical review of research methods. In A. Cowie (ed.), The dictionary and the language learner, Tubingen, Max Niemeyer Verlag: 11-28. 
Hosenfeld, C. 1977. A Preliminary Investigation of the Reading Strategies of Successful and Nonsuccessful Second Language Learners. System 5: 110-23.

Hulstjin, J.H. 1993. When do foreign language readers look up the meaning of unfamiliar words? The influence of task and learner variables. The Modern Language Journal 77(2): 139-147.

Knight, S. 1994. Dictionary use while reading: The effects on comprehension and vocabulary acquisition for students of different verbal abilities. The Modern Language Journal 78: 285-299.

Laufer, B. 1997. The Lexical Plight in Second Language Reading: Words you don't Know, Words you Think you Know, and Words you can't Guess. In J. Coady and T. Huckin (eds.), Second Language Vocabulary Acquisition. Cambridge: Cambridge University Press: 20-34.

Laufer, B. and Hadar, L. 1997. Assessing the effectiveness of monolingual, bilingual and 'bilingualized' dictionaries in the comprehension and production of new words. The Modern Language Journal, 81: 189-196.

Laufer, B. and Hill, M. 2000. What lexical information do L2 learners select in a CALL dictionary and how does it affect word retention? Language Learning and Technology 3: 58-76.

Luppescu, S. and Day, R.R. 1993. Reading, dictionaries and vocabulary learning. Language Learning, 43: 263-287.

Nation, P. 2001. Learning vocabulary in another language. Cambridge: Cambridge University Press.

Nesi, H. and Haill, R. 2002. A study of dictionary use by international students at a British university. International Journal of Lexicography 15(4): 277-305.

Nesi, H. and Hua Tan, K. 2011. The effect of menus and signposting on the speed and accuracy of sense selection. International Journal of Lexicography 24 (1): 79-96. $\ln 1$

Neubach, A. and Cohen, A.-D. 1988. Processing strategies and problems in the use of dictionaries. Journal of the dictionary society of North America 10: 1-19.

Oxford, R. 1990. Language Learning Strategies: What every teacher should know. New York: Newbury House Publishers. 
Schmitt, N. 1997. Vocabulary learning strategies. In N. Schmitt and M. McCarthy (eds.), Vocabulary: Description, Acquisition and Pedagogy. Cambridge: Cambridge University Press: 199-227.

Scholfield, P. 1999. Dictionary Use in Reception, International Journal of Lexicography 12(1): 13-34.

Scholfield, P. 2002. Why Shouldn't Monolingual Dictionaries be as Easy to Use as Bilingual Ones? [Retrieved June 10, 2010, from http://www.longman.com/ dictionaries/teachers/articles/p-scholfield-02.html].

Summers, D. 1995. The Role of Dictionaries in Language Learning. In R. Carter and M. McCarthy (eds.), Vocabulary and Vocabulary Teaching. Harlow and London: Longman: 111-125.

Wingate, U. 2004. Dictionary use - the need to teach strategies. Language Learning Journal, 29: 5-11. 


\section{Appendix}

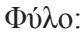

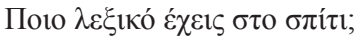

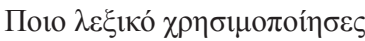

\section{$\underline{\mathrm{XPH} \Sigma \mathrm{H} \Lambda \mathrm{E} \Xi \mathrm{IKOY}}$}

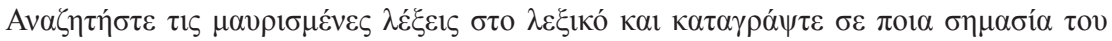

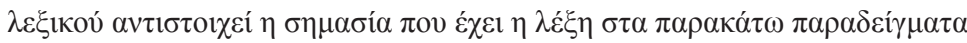

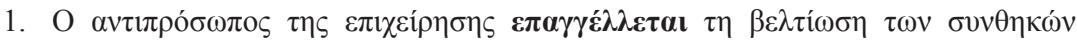

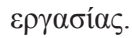

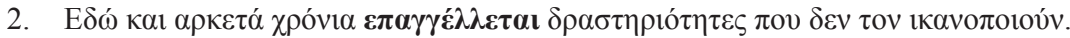

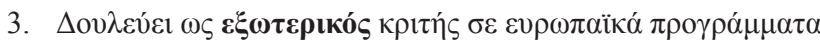

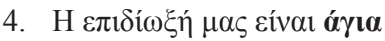

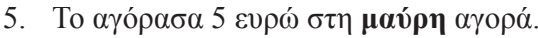

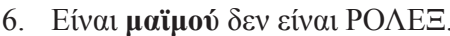

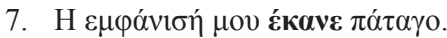

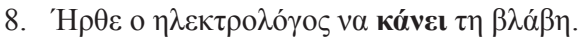

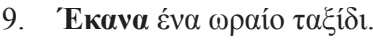

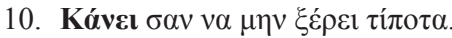

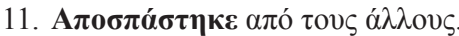

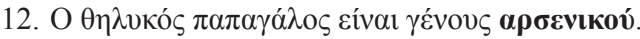

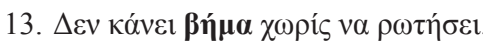

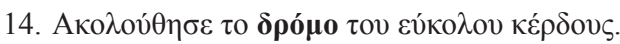

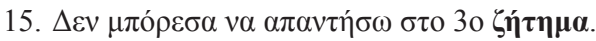

